\title{
Effect of novolac on mechanical and physical properties of nitrile rubber (NBR)
}

\author{
Mohammed H. Al-Maamori ${ }^{1}$, Ali Abdul-Amir Al-Zubaidi ${ }^{2}$, Ahmed Abdulameer Subeh ${ }^{1}$ \\ ${ }^{1}$ College of Materials Engineering, Babylon University, Department of Polymer and Petrochemical Industries, Babylon, Iraq \\ ${ }^{2}$ College of Engineering / Al-Musayyib, Babylon University, Babylon, Iraq
}

\section{Email address:}

mhalmaamori1959@yahoo.com (M. H. Al-Maamori), axzy128@yahoo.com (A. A. Al-Zubaidi), ahmedeng6217@yahoo.com (A. A. Subeh)

\section{To cite this article:}

Mohammed H. Al-maamori, Ali Abdul-Amir Al-Zubaidi, Ahmed Abdulameer Subeh. Effect of Novolac on Mechanical and Physical Properties of Nitrile Rubber (NBR). International Journal of Materials Science and Applications. Special Issue: Steel and Direct Reduced Iron (Sponge Iron) Industry. Vol. 4, No. 2-1, 2015, pp. 43-47. doi: 10.11648/j.ijmsa.s.2015040201.18

\begin{abstract}
This research aims to study the effect of addition novolac material (phenol formaldehyde resin, polar) on the mechanical and physical properties of nitrile rubber (NBR) and the proportion of addition novolac material is $(0,10,20,30,40,50$ pphr) to a sample of nitrile rubber containing 40 part per hundred rubber (pphr) carbon black as a proportion stationary been prepared with (factors of vulcanization, accelerators and activators using two-roll mill laboratory, molds, thermal piston and difference of examination conditions from pressure, temperature and time according to the ASTM), all tests were conducted in the laboratories of the college of materials engineering - university of babylon and laboratories of babylon tire company. Then carrying out the process of scheduling the results of laboratory testing and study its diagrams. Where the results showed the mechanical properties increase in hardness, modulus of elasticity, and resistance to compression, and improved a little in the tear resistance, especially when the amount of novolac are 10 and $20 \mathrm{pphr}$, and a decrease in properties (tensile strength, elongation at break and resilience), also results show increase in adhesion with polyester fibers and nylon fibers when increasing novolac material. While the results of the physical properties show primitive increase in viscosity, the greatest torque twisting, scorch time and cure time, then decrease for to increasing novolac material. specific gravity also increases with increasing novolac material.
\end{abstract}

Keywords: Nitrile Rubber (NBR), Novolac, Mechanical and Physical Properties

\section{Introduction}

Rubber has limited applications without reinforcement.so that be added polymeric materials including novolac resin to the rubber to reduce the cost and improve the mechanical properties, the properties of adhesion and high temperature resistance, that meaning the study of mechanical and physical properties of various engineering materials is considered important because of its engineering applications.

The growing use of rubber in engineering applications results from its unique properties that include high extensibility, high strength, high-energy absorption, and high resistance to fatigue. Other attributes are good environmental resistance and high resilience. Engineered rubber products consist of all rubber, or rubber combined with other materials. Product complexity ranges from that of a simple rubber band to complex composites such as radial tires or rubber-metal bearings for use in aerospace applications [1].
Nitrile Rubber (NBR) is commonly considered the workhorse of the industrial and automotive rubber products industries. NBR is actually a complex family of unsaturated copolymers of acrylonitrile and butadiene. By selecting an elastomer with the appropriate acrylonitrile content in balance with other properties, the rubber compounder can use NBR in a wide variety of application areas requiring oil, fuel, and chemical resistance. In the automotive area, NBR is used in fuel and oil handling hose, seals and grommets, and water handling applications [2].

With a temperature range of $-40^{\circ} \mathrm{C}$ to $+125^{\circ} \mathrm{C}$, NBR materials can withstand all but the most severe automotive applications. On the industrial side NBR finds uses in roll covers, hydraulic hoses, conveyor belting, graphic arts, oil field packers, and seals for all kinds of plumbing and appliance applications. Worldwide consumption of NBR is expected to reach 368,000 metric tons annually by the year 2005 [2]. 

[3].

NBR is produced in an emulsion polymerization system

Novolac is a Phenolic or Phenol formaldehyde (PF) resins were the first polymeric resins produced commercially from simple low molecular weight compounds [4].

Novolacs are formed by the acid catalysed reaction of formaldehyde and phenol in the ratio between 0.5:1 to 0.9:1. The reaction between phenol and formaldehyde in the acidic $\mathrm{pH}$ range occurs as an electrophilic substitution. The catalysts most frequently used are oxalic acid, hydrochloric acid, sulphuric acid, p-toluene sulphonic acid (PTSA) or phosphoric acid. Most commonly, oxalic acid is preferred because colourless resins may be prepared. In addition, oxalic acid decomposes at high temperatures to $\mathrm{CO}_{2}, \mathrm{CO}$ and water, and thus oxalic acid will be excluded from recipe. Typically, 1 - 6 weight $\%$ catalyst is used [5-7].

Novolac resins which are thermoplastic in nature must generally be cured by addition of a cross-linking agent. The most widely used curing agent is hexamethylenetetramine (HMTA or hexa). Most commonly 8-15 weight $\%$ of HMTA is used [8].

- Al-Maamory, M.H. 2005[9]. studied the effect of adding navolacin the range of 0-50 pphr, depending on the mechanical and thermal properties to give the batch the ability to absorb shocks and vibrations generated in motor vehicles.

- Muhannad K. D. 2007[10]. The researcher studied reinforcement technique -with copolymer matrix elastomer (Nitrile butadiene rubber), and thermosetting resin (novolac) as follows: Addition of novolac resin 0$50 \mathrm{pphr}$ gives a good mechanical and thermal properties which are the principal reason for its uses for the new composite material (hard material use in cloth drawing roller). At $30 \mathrm{pphr}$ hardness and tensile strength values are 75.25 IRHD, 10.787 Mpa respectively.

- The aim of this research to study the effect of adding variable amounts of novolac resin on various properties of nitrile rubber.

\section{Materials and Methods}

\subsection{Materials Used}

Nitrile rubber (NBR), Zinc oxide, Stearic acid, Tetramethylthiuramdisulfide(TMTD),Mercaptobenzothiazold isulfide (MBTS), Hexamethylene Tetramine (HMT), Castor oil, Sulfur, 2,2,4-trimethy 1,1,2-dihydroquinoline (TMQ), Carbon black (N 326) and novolac used in this study.

\subsection{Preparation Method}

The formulation of the rubber composites are given in Tables (1) .

Mixing was carried out in a two-roll mills, operations of kneading and mixing took place on this equipment according to ASTM D 15.

The ingredients were added according to ASTM D3187-89 as follows:
1 Passing NBR between the two rolls several times with decreasing the distance between the two rolls to the extent of (0.5-1) mm .

2 Addition of sulfur follow by mixing for homogenization of the materials under room temperature.

3 Add stearic acid, zinc oxide, with the remaining quantity from sulfur step (2) together, follow by mixing for homogenization of the materials.

4 Add half of the carbon black with operating oil evenly across the mill at a uniform rate.

5 When this portion of the carbon black has been completely incorporated, open the rolls to $1.65 \mathrm{~mm}$ (0.065 in.).

6 Add the remaining carbon black and oil evenly across the rolls at a uniform rate.

7 Addition of accelerator TMTD and MBTS With the addition of antioxidant TMQ this is followed by mixing materials for the purpose of homogenization.

8 Set the rolls at $0.8 \mathrm{~mm}$ ( $0.032 \mathrm{in}$.), follow by mixing for homogenization of the materials.

9 Add materials (such as novolac) with mixing and homogenizing.

10 Add (HMT) after the addition of Novolac.

11 Open the mill to give a minimum batch thickness of 6 $\mathrm{mm}(0.25 \mathrm{in}$.) and The mixing process continues for more time in order to get a good homogenization.

After preparation of recipes rubber composite by two-roll mill laboratory, examination models are prepared to provide (moldings and condition of examination such as temperature, pressure and time) then a process of vulcanization by the thermal piston, according to the ASTM.

Table (1). The composition of the rubber composites

\begin{tabular}{|c|c|c|c|c|c|c|c|}
\hline \multirow{2}{*}{$\begin{array}{l}\text { Item } \\
\text { No. }\end{array}$} & \multirow{2}{*}{$\begin{array}{l}\text { Recipe } \\
\text { Ingredients }\end{array}$} & \multicolumn{6}{|c|}{ Loading level (pphr) } \\
\hline & & (1) & $(2)$ & (3) & (4) & (5) & (6) \\
\hline 1 & NBR & 100 & 100 & 100 & 100 & 100 & 100 \\
\hline 2 & Activator (zinc oxide) & 3 & 3 & 3 & 3 & 3 & 3 \\
\hline 3 & $\begin{array}{l}\text { Activator (stearic } \\
\text { acid) }\end{array}$ & 1 & 1 & 1 & 1 & 1 & 1 \\
\hline 4 & Carbon black N-326 & 40 & 40 & 40 & 40 & 40 & 40 \\
\hline 5 & Castor oil & 10 & 10 & 10 & 10 & 10 & 10 \\
\hline 6 & Anti-Oxidant (TMQ) & 3 & 3 & 3 & 3 & 3 & 3 \\
\hline 7 & Accelerator (TMTD) & 2 & 2 & 2 & 2 & 2 & 2 \\
\hline 8 & Accelerator (MBTS) & 1 & 1 & 1 & 1 & 1 & 1 \\
\hline 9 & Sulfur & 1.5 & 1.5 & 1.5 & 1.5 & 1.5 & 1.5 \\
\hline 10 & Novolac & 0 & 10 & 20 & 30 & 40 & 50 \\
\hline 11 & HMT & 0 & 1 & 2 & 3 & 4 & 5 \\
\hline
\end{tabular}

\section{Characterization and Testing}

\subsection{Mechanical Properties Test}

\subsubsection{Tensile, Elongation, and Modulus Test}

Tests are carried on samples which are prepared (cutting three dumbbell specimen) from the vulcanized slice the cutting take place by hand press.and according to the ASTM d412-88 by Monsanto T10 tensometer by using special jaws for holding tensile test sample which is movable by speed of $500 \mathrm{~mm} / \mathrm{min}$. 


\subsubsection{Tear Resistance Test}

Examination carried out according to standard ASTM D624-54, by a device tensile (Tansometer10) and speed (500 $\mathrm{mm} / \mathrm{min}$ ) after setting the model examination (dumbbell) by cutting machine models and the work of the incision in the narrow area of the model by cutting machine (Nicking cutter) type (Wallace). Then examination by a Tansometer10 to give the results $(\mathrm{N} / \mathrm{mm})$.

\subsubsection{Hardness Test}

The test was carried out under ASTM-D2240 Standard using durometer (Hardness shore A). standardized hardnessmeasuring equipment, a sharp needle was applied directly on to the surface of specimens to measure hardness . data were averaged over six different positions .

\subsubsection{Specific Gravity Test}

The density tester machine is used . the specification of this machine were digital accuracy $=0.0001 \mathrm{~g} / \mathrm{cm}^{3}$, type GP120 S, (Matsu Haku, China). first weight the sample (hardness sample) in air then in water at $23^{\circ} \mathrm{C}$, by using the equation (Specific gravity $=$ [sample weight in air/(sample weight in air - sample weight in water)] $*$ Specific gravity of liquid).

\subsubsection{Resilience Test}

Resiliency is checked according to specification (ASTM D1054) using device (Wallace Dunlop Tripsometer) linked to a digital computer information "Wrpra-wallace Rebound Resilience Data Computer" records the percentage of resilient.

\subsubsection{Adhesion Test}

Tests are carried on prepared samples according to the ASTM 2229 by tensometer T10 in which we exchange the special jaws for adhesive test which is movable with speed of $50 \mathrm{~mm} / \mathrm{min}$ for measurement the adhesion with wires and with textile.

\subsubsection{Compression Set Test}

Compression set test (ASTM D395) was performed on standard test specimen of cylindrical shape of $29 \pm 0.5 \mathrm{~mm}$ diameter and $12.5 \pm 0.5 \mathrm{~mm}$ thickness. Samples were compressed to $40 \%$ of its thickness for 72 hours in compression set device, then it is left for $30 \mathrm{~min}$ before taking the final thickness of the samples.

\subsection{Physical Properties Test}

\subsubsection{Viscosity and Curing Characteristics Test}

The test carry on according to ASTM D2084-89 by using Oscillating dick Rheometer (ODR) for samples prepared (cutting from recipes rubber composite) in which its control by upper and lower jaws clutch under $20 \mathrm{~Pa}$ and $185^{\circ} \mathrm{C}$ for 6 $\min$.

The result draw as a graph of Torque vs. Vulcanized time as pointed out the following data (maximum torque (1b-in), minimum torque $(1 \mathrm{~b}$-in), scorch time $(\mathrm{min})$, cure time (min) ,viscosity $\left(\mathrm{ML}^{*} 2.71\right)$ ). The rehometer links to a computer with a precision control program .

\section{Results and Discussions}

\subsection{Discuss the Results of the Mechanical Properties Test}

\subsubsection{Tensile (Mpa), Elongation (\%), and modulus (100\% Mpa) Tests}

Figure 1 shows a decrease in tensile strength when adding novolac material, because the branching side or the entanglements crystalline worked by (the polar phenol) is that reduce the tensile strength of the composite rubber product when shed stress in the direction of the longitudinal axis of the chains rubber as a result of the growth of some micro cracks that cause failure in tensile strength with the increasing the strength of the rubber compound, as a result of the increasing proportions load of novolac.

But in Figure 2, results found that the elongation also decreases for the same reasons above, with the other reason is to increase the volumetric fraction of the novolac [10] within the rubber composition of the synthetic rubber (NBR). Modulus of elasticity rises with the increasing novolac material because of the formation of aggregates side and increase the number of links interrelation (entanglements), as in Figure 3.

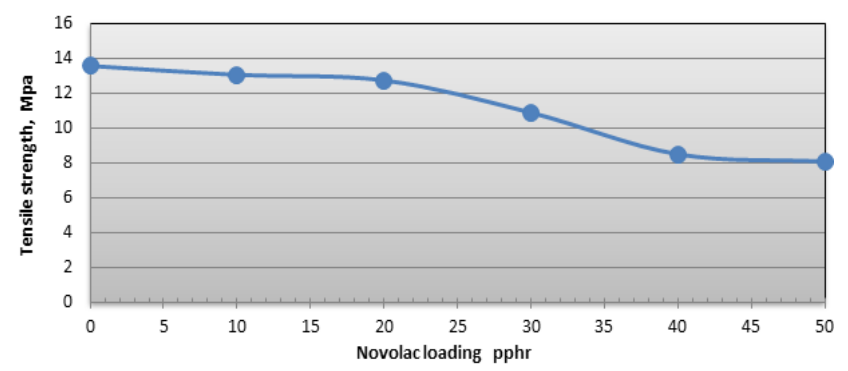

Figure 1. Effect of Novolac (pphr) on the tensile strength of NBR matrix composite

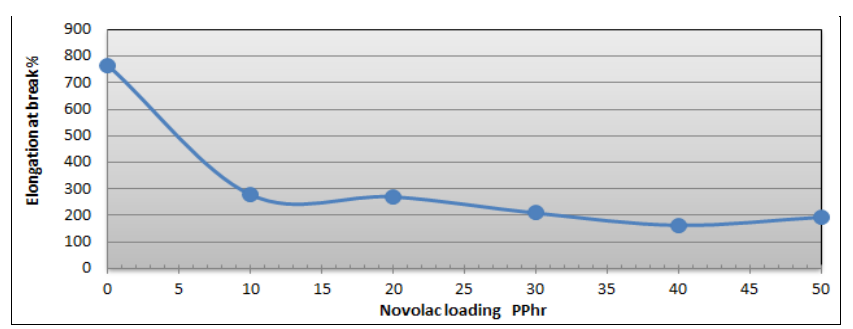

Figure 2. Effect of Novolac (pphr) on the elongation of NBR matrix composite.

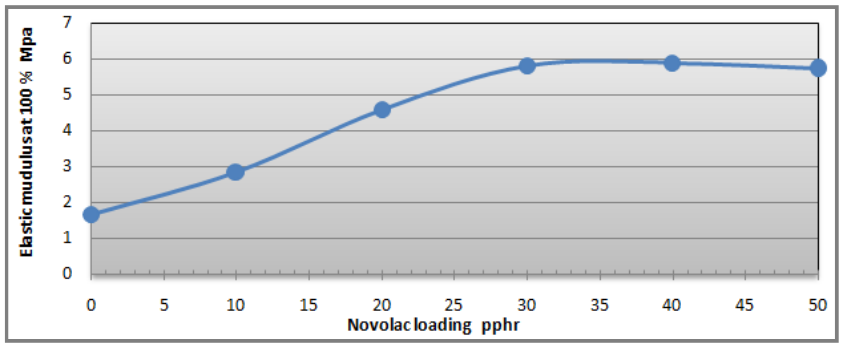

Figure 3. Effect of Novolac (pphr) on the modulus of NBR matrix composite. 


\subsubsection{Tear Resistance Test (Mpa)}

Figure 4 shows the effect of adding novolac material on (tear resistance), which is measured in units of Mpa. It is found that recipes rubber increase their tear resistance with the increasing novolac load until $20 \mathrm{pphr}$ this is because of the early starting crosslinking of the chains, but after $20 \mathrm{pphr}$ increased entanglements and decrease in tear resistance.

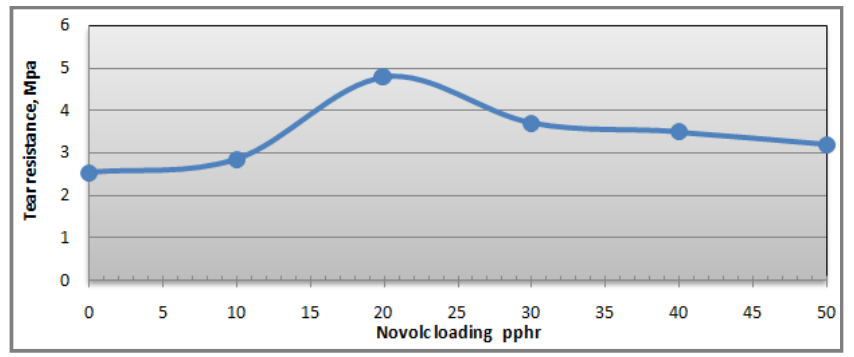

Figure 4. Effect of Novolac (pphr) on the Tear resistance of NBR matrix composite

\subsubsection{Hardness Test ( $\operatorname{Sh} A)$}

Figure 5 shows the relationship between the hardness and the addition weights of novolac to the recipe rubber composite, results showed that increasing the proportion of novolac which leads to increased hardness. The increase in hardness is attributable to strong tangles between the rubber and the novolac which produces an increase in surface tension. It means that the surface of the product becomes resistant to penetration [9].

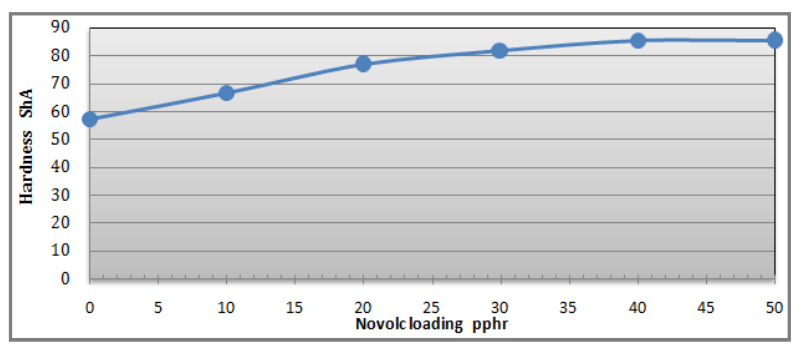

Figure 5. Effect of Novolac (pphr) on the hardness of NBR matrix composite

\subsubsection{Specific Gravity Test}

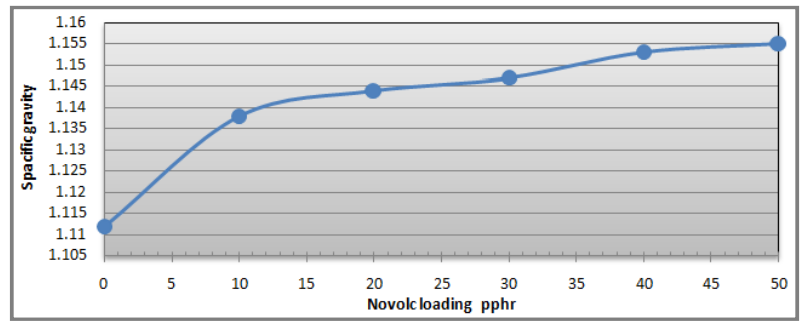

Figure 6. Effect of Novolac (pphr) on the Specific gravity of NBR matrix composite

Figure 6 shows the relationship between specific gravity and proportions of novolac added to recipe rubber composite, it is noted an increase in specific gravity with the increase in the proportion of the novolac, and this behavior is attributed to the lack of spaces between the rubber chains because novolac enters between the rubber chains and thereby dictate voids. i.e rubber recipes at high temperature become stiff thus no gaps or cracks inside the recipes rubber, in addition to that novolac has specific gravity (1.3), higher than that (1.09).

\subsubsection{Resilience Test}

Addition of novolac to the industrial rubber compound (nitrile rubber) causes a small increase in the resilience up to the $10 \mathrm{pphr}$, then followed by a decrease in the resilience due to increased hardness resulting from the increase in the density of the branching side, which lead to increased energy absorbed by the composite rubber, as in figure 7 .

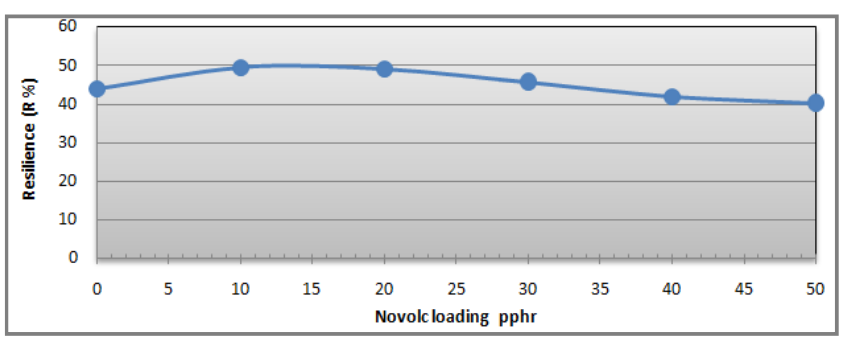

Figure 7. Effect of Novolac (pphr) on the Resilience of NBR matrix composite.

\subsubsection{Adhesion Test}

Figure 8 shows the increase in the strength of adhesion with the increasing novolac addition, the reason is to increase the density of interrelation of compound rubber, which leads to increased adhesion with fibers (polyester and nylon), as the proportion reach 20 and $30 \mathrm{pphr}$ the adhesion of novolac with polyester fibers higher than with nylon fibers, when the proportion exceed $50 \mathrm{pphr}$ the adhesion decreases for both fibers.

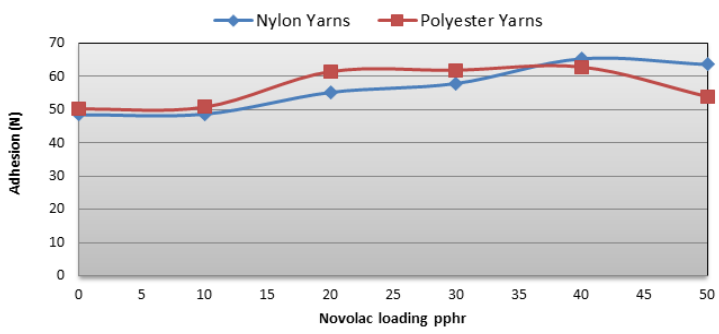

Figure 8. Effect of Novolac (pphr) on the Adhesion of NBR matrix composite.

\subsubsection{Compression Set Test (\%)}

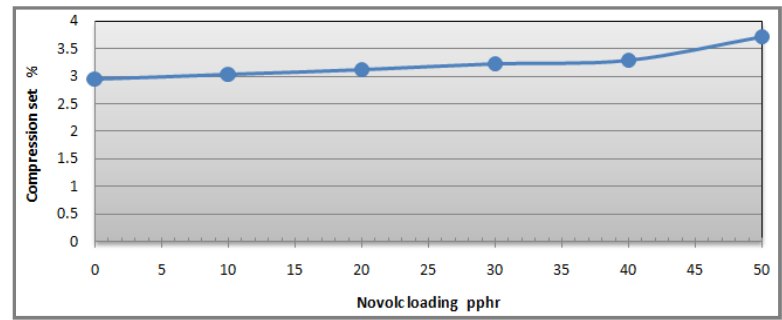

Figure 9. Effect of Novolac (pphr) on the Compression set of NBR matrix composite

Results showed that the compressive strength increases with the proportion of the novolac, this is because the 
increase in the density of entanglements and a decrease in the movement of rubber chains and increase the rigidity or stiffness compound rubber, and these entanglements reduce susceptibility retrieval of compound rubber, and this result agree with the results of two former researches [11] as in Figure 9.

\subsection{Discuss the Results of the Physical Properties Test}

\subsubsection{Viscosity (Mooney) \& Max. Torque (MH lb*inch).}

Figure 10 shows the relationship between viscosity and the proportion of the novolac added to recipe rubber composite, noticed an increase of viscosity with the increasing the novolac because it has the characteristics of elastomeric material at a temperature of $185^{\circ} \mathrm{C}$ but after reaching $20 \mathrm{pphr}$ novolac or above, the viscosity and fluctuating becomes low because of the reverse effect to increase the hardness and density of entanglements. At the same shape note a rise in the values of the greatest torque twisting, Any more pressure needs to purpose of recipe flow inside the mold as a result of entanglement, which do the novolac with rubber chains, but after reaching a 30 pphr novolac fluctuating in the torque values for the same reasons above.

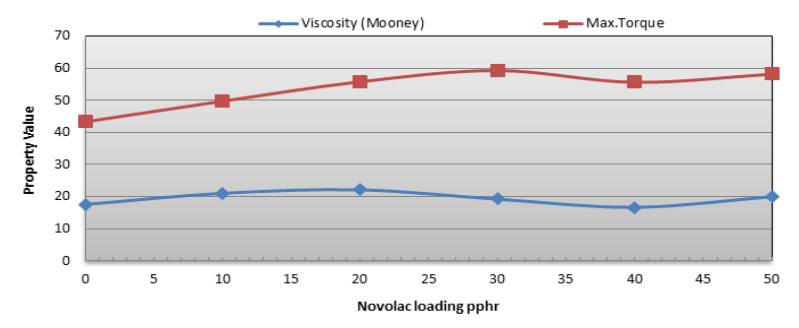

Figure 10. Effect of Novolac (pphr) on the (Viscosity, Max. Torque) of NBR composite.

\subsubsection{Scorch Time (TS5 Min) \& Cure Time (TC90 Min)}

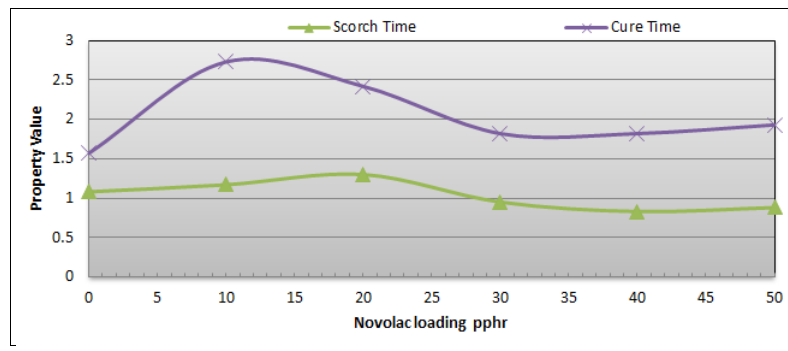

Figure 11. Effect of Novolac (pphr) on the (Scorch Time, Cure Time) of NBR composite.

Figure 11 shows the relationship between scorch time and the ratio of the novolac. The increase in the proportion of the novolac leads to a small increase in the Scorch time and then decreases in the value, this is attributed to the entry of the novolac with chains during a rubber vulcanization process, which link rubber chains, thereby reducing the Scorch time. The same figure shows the relationship between the time of vulcanization (cure time) and the ratio of the novolac, It is noted that increase in the proportion of the novolac leads to the increasing time of vulcanization and the reason for this is the amount of materials solidified (HMT) that are initially good down to the $10 \mathrm{pphr}$ of the novolac after this they become few and they are inadequate to strengthen (hardness) each quantity of the novolac, and therefore rubber need more time to complete the process of vulcanization.

\section{Conclusions}

1 New polymer composites were prepared from the mixing novolac with (NBR).

2 Tensile strength decrease (from 13.579 Mpa to 8.085 Mpa) with increasing the novolac content .

3 Elongation at break decrease (from $767 \%$ to $193.5 \%$ ) with increasing the novolac content .

4 modulus of elastcity increase (from 1.66 Mpa to 5.716 Mpa ) with increasing the novolac content .

5 Hardness increase (from 57.2 to 85.166 ShA ) with increasing the novolac content.

6 Other properties such as tear resistance, compression set and specific gravity increase, but resilince decrease with increasing the novolac content .

7 Physical properties such as viscosity, max.Torque, scorch time, cure time, their values varies with increasing the novolac content .

8 Best adhesion with the fiber at $40 \mathrm{pphr}$ novolac.

\section{References}

[1] J. G. Sommer, Rubber World, December, 1996, p. 18.

[2] Table 2, Worldwide Long Term New Rubber Consumption Forecast by Elastomer Type, IISRP Worldwide Rubber Statistics (2001).

[3] Table 14, Nitrile Dry Rubber (NBR), IISRP Synthetic Rubber Manual,13th Edition, (1995).

[4] A.Knop and W.Scheib, Chemistry and Application of Phenolic Resins, Springer-Verlag,Berlin Heidelberg, New York (1979).

[5] N.Kornblum, R.A.Smiley, R.K.Blackwood and D.C.lffland, J. Amer. Chem.S0c. 77, 7269 (1955).

[6] Humayun Manda] and Allan S. Hay, Polymer, 38 ,26, 62676271(1997).

[7] Martin R.W. The Chemz'stry of Phenolic Resz'n.s', New York, J .Wei1y, (1956).

[8] Kopf P.W., Wagner,E.R., Polym.Sci. Poly. Chem. Ed.,11, 939 (1973).

[9] Al-Maamory, M.H " Mechanical \& Physical Properties of Rubber Composite For Engine Mounting " Ph. D. thesis, University of Technology, Baghdad, 2005.

[10] Muhannad Kh. D. " Design and Industrialization Recipes of Cloth Drawing Rollers From Rubber composite material " M. D. thesis, University of Babylon, 2007.

[11] Schuur MVD, Gaymans RJ. Influence of chemical crosslinks on the elastic behavior of segmented block copolymers. Polymer 2005;46:6862-8. 